

\title{
Noir Dourado da adaptação literária: de Rubem Fonseca ao clichê da minissérie Agosto
}

\author{
Golden Noir in literary adaptation: from Rubem Fonseca to the \\ 'agosto' mini-series cliché
}

Marcelo Magalhães Bulhões*

\begin{abstract}
Resumo: O propósito deste artigo é avaliar a adaptação de Agosto, romance de Rubem Fonseca publicado em 1990, produzida pela TV Globo. Tal avaliação buscará acessar a questão da adaptação audiovisual como fenômeno intersemiótico, enfocando um gênero cuja trajetória histórica é exemplar da dinâmica de absorção, transformação e recriação que envolve as relações entre cinema e literatura: o noir.
\end{abstract}

Palavras-chave: Adaptação literária. Noir. Televisão. Cinema.

Abstract: The purpose of this article is to evaluate the adaptation of 'Agosto' (August) - a novel by Rubem Fonseca - produced by TV Globo television. Such evaluation will try to assess the issue of audiovisual adaptation as an intersemiotic phenomenon, focusing on a genre whose history is an example of the dynamics of absorption, transformation and recreation that involves the relationships between movies and literature: the noir fiction.

Key words: Literary adaptation. Noir. Television. Cinema.

* Professor do Programa de Pós-graduação em Comunicação da Unesp. Livredocente em Teoria Literária (Unesp), Doutor em Literatura Brasileira, Mestre em Teoria Literária. 


\section{Introdução}

Agosto, minissérie televisiva produzida pela TV Globo e exibida em 1993, inscreve-se claramente na tradição cinematográfica do gênero noir. Ao fazer isso, a minissérie portaria em sua estrutura visual uma estilística do noir por este ser o gênero diretamente associado à obra homônima de Rubem Fonseca, na qual a minissérie se baseia. À primeira vista, pois, a minissérie realizaria uma correspondência ou equivalência da expressão audiovisual à sua "matriz" literária. Mas tal "primeira vista" pode ser revista.

A explícita marca do gênero noir em uma produção televisiva pode render alguns dividendos proveitosos para se tratar do problema da adaptação na contemporaneidade em dimensões mais dilatadas. É que desde sua origem, nos Estados Unidos dos anos 40, o gênero noir viveu uma intensa relação entre literatura e cinema, diálogo que se afirmaria anos afora. Tomo como fundamento para a noção de gênero - o que inclui o romance de Rubem Fonseca, a adaptação na minissérie e o próprio ciclo de filmes noir dos anos 40 e 50 - contribuições teóricas no lastro da moderna teoria literária que encaram os gêneros como categorias historicamente situadas e apreendidas pela via empírica. Assim, um autor como Mikhail Bakhtin (1988) nos adverte do vínculo indissociável entre particulares contextos socioculturais e da esfera da vida material e as específicas soluções formais e temáticas que norteiam gêneros. Nessa trilha, o mesmo Bakhtin assinala que os gêneros vivem a constante relação dialética permanência/transformação, na qual reiteração ou rotinização de procedimentos formais associados a motivos temáticos e universos narrativos convive com sua irreprimível e iminente mutação, em consonância - embora nunca de modo mecânico - com dimensões da esfera econômica e social.

Para a necessária articulação, cara aos interesses deste artigo, entre a noção de gênero e a estética noir vale a noção de estilo cinematográfico pelo uso que faz dele David Bordwell (2013). Nessa perspectiva, o estilo cinematográfico diz respeito ao 
uso sistemático de traços característicos, recorrentes e, portanto, reconhecíveis em um conjunto de obras cinematográficas - ou audiovisuais de modo mais amplo, o que permite incluir minisséries de televisão. Assim, considerar o noir um gênero cinematográfico implica identificarem-se procedimentos responsáveis por uma estrutura audiovisual discernível, caracteres que se imprimem em uma série de filmes. Pode-se, é verdade, falar em estilo como marca pessoal de um diretor, mas esse uso não pode interessar a uma visada que busca apreender o que é comum a um corpo de filmes - inseparáveis de um momento da história do audiovisual. Assim, em termos metodológicos, a minissérie Agosto foi cotejada com uma série de filmes produzidos sob a designação noir ${ }^{1}$ no período considerado por distintos pesquisadores, caso de Silver e Ursini (1999) ou Mattos (2001), como “clássico, ou seja, do início da década de 40 ao fim dos anos 50". E o trabalho de cotejo, a partir de uma seleção de cenas de filmes noir e da minissérie Agosto, levou em consideração o uso de técnicas que para Bordwell (2013, p. 17) respondem pela noção de estilo: mise-en-scène (encenação, iluminação, atuação de atores e ambientação), enquadramento, manejo de dimensões cromáticas e montagem.

Por fim, vale mencionar a classificação de Agosto como minissérie televisiva segundo o olhar de Renata Pallottini (2012), que a entende como um programa que possui de cinco a vinte capítulos em média, duração que, embora arbitrária, é sempre muito inferior ao tempo de uma telenovela. Lembra Pallotini que se por um lado a minissérie compartilha com a telenovela uma unidade que se completa na visão da totalidade dos capítulos e no conjunto do assunto, por outro se assemelha mais a um filme longo de cinema (PALLOTTINI, 2012). Tal aspecto é importante para o caminho analítico deste artigo, uma vez que se entreverão modos de associação entre a minissérie Agosto e o universo cinematográfico noir.

1 Utilizou-se para a análise fílmica a coleção "Filme Noir", lançada a partir de 2015 pela produtora Versátil Home Video, coletânea em diversos volumes de filmes do período "clássico" do gênero. 
Ao longo de décadas, o consórcio literatura-cinema do noir aportaria a outros afluentes narrativo-ficcionais que alargariam seu circuito e promoveriam mais complexidade à questão da "influência". Tal é o caso de narrativas de grande consumo na indústria cultural, como as histórias em quadrinhos e as minisséries televisivas. Mais recentemente, a grande expansão das narrativas digitais levou as marcas irreconhecíveis do noir para os games. O noir oferece-se, assim, como um território franco e dinâmico em que circulam e se contaminam signos, códigos, linguagens e configurações narrativas em distintos meios. Tal valor do noir está, então, colado ao propósito deste artigo, com o necessário recorte: avaliar a adaptação televisiva da minissérie Agosto no cerne do fenômeno da tradução intersemiótica.

Embora a designação adaptação possa ser - já a fora várias vezes - considerada inadequada ou insuficiente, tomo-a para se referir a um fenômeno que há muito deixou de ser problema exclusivo de "transposição" do literário para o cinematográfico, pois é território povoado de diversos sistemas de signos, em conluio e espelhamento constante. Se no passado a literatura fora a principal mumificadora para o gênero se trasladar em realização fílmica; na contemporaneidade assiste-se a toda sorte de câmbios e inflexões entre distintas expressões narrativo-ficcionais.

Naturalmente o fenômeno não é exclusivo do noir. E justamente por isso o "caso" noir pode servir à verificação de outras manifestações semelhantes, ao vislumbre de circuitos e trocas recíprocas entre procedimentos estéticos, configurações narrativas, gêneros, meios, cujas singularidades são coligadas aos peculiares contextos de produção e difusão midiática. Assim, um quadrinho ou graphic novel - como Sin City: a Cidade do Pecado, de Frank Miller, recicla a tradição literário-cinematográfica do noir e sua adaptação para o cinema traz a marca de um hiperrealismo visual - com expedientes do meio digital - que remete ou "devolve" o universo dos quadrinhos ao espectador.

Menciono Sin City como um caso, entre tantos, de como 
na contemporaneidade se se intensifica identificação de uma fonte matricial da expressão narrativo-ficcional. No limite, está invalidada a própria noção de fonte ou matriz municiadora. L.A. Noire, por exemplo - produzido pela companhia Rockstar Games e lançado em 2011 -, é um game cuja etiqueta noir é tributária do meio cinematográfico. Mas logo se flagra o movimento em direção contrária ou em ocorrência concomitante em diversas produções do cinema atual de mainstream "inspiradas" nos games.

Se a adaptação, portanto, está "em toda parte", avaliar como uma minissérie televisiva se enlaça a um gênero privilegiadamente simbiótico entre os códigos verbal e o audiovisual deve ser caminho válido para a discussão mais dilatada sobre as relações entre códigos e processos narrativos no cenário midiático, no jogo voraz e incoercível de trocas, congregações, conflitos e interposições entre gêneros e linguagens da ficção midiática contemporânea.

\section{Página e tela}

O que historicamente é conhecido como film noir procede da designação de críticos franceses a um circuito de filmes americanos cujo auge ocorreu entre as décadas de 1940 e 1950. A descoberta pela crítica francesa de tais filmes deveu-se a um fator de ordem histórica, pois a partir da Segunda Guerra - e com a ocupação nazista - a França ficou privada durante quase cinco anos da exibição de filmes americanos. A designação noir acunhada pela crítica francesa traz uma identificação que amarra o cinematográfico ao literário "de massa". Tal nomeação era inspirada na Série Noire, coleção de capa preta criada por Marcel Duhamel em 1945 para a editora Gallimard. Tratava-se de romances populares americanos de trama policial-detetivesca - uma literatura pulp ficcion - cujos principais escritores eram Dashiell Hammett, Raymond Chandler e James M. Cain. Não por acaso, romances como O Falcão Maltês, de Hammett, À Beira do Abismo e Adeus, Minha Adorada, de Chandler, ou $O$ Destino Bate à Porta, de Cain, figuram como 
adaptações cinematográficas que imprimem a marca reconhecível ao gênero filme noir logo na sua arrancada. Aos olhos da crítica francesa tais filmes pareciam "escuros", "noturnos", "negros".

Se a origem do que se conheceria como noir se encontra, nas décadas de 1920 e 30, na publicação pela revista Black Mask de narrativas de escritores como Hammett, Chandler e Cain e migra para adaptações cinematográficas no universo hollywoodiano nos anos 40 e 50, no correr de décadas cada vez mais haveria um movimento recíproco de contaminação entre cinema e literatura. Décadas à frente se tornariam mais claros os sinais de "influência" que a literatura noir recebe do cinema com procedimentos do sistema verbal que funcionariam como correlativos à estética do "filme negro". De outra parte, a plasticidade obscura que se tornaria emblema do gênero acusaria a marca privilegiadamente cinematográfica. Afinal, os contos e romances policiais de Dashiell Hammett, Raymond Chandler ou James Cain não eram especialmente "negros", não exploravam enfaticamente a obscuridade ou noturnismo nas descrições. Foi a inflexão da estética expressionista - com a presença de técnicos e diretores de cinema migrados da Europa nos estúdios de Hollywood - que dotou as adaptações de um noturnismo visual que se afinava ao teor assustador das tramas criminosas de tais escritores; a recorrência de procedimentos de composição cinematográfica "negra" infundida pelo Expressionismo foi consagrando de tal modo a peculiaridade de uma estrutura visual a ponto de se falar em estilística visual noir que, por sua vez, passou a ser vista como consorciada a temas e enredos da chamada literatura de Hammett, Cain e Chandler.

O destino do noir seria, pois, como tantos outros gêneros, o de novas acomodações e entrelaçamentos, esparzindo-se em contexto trans-nacional, aclimatando-se e acoplando novos processos estético-narrativos em um movimento intertextual que chega a retificar ou subverter sua "matriz". Uma dessas aclimatações "desobedientes" é a obra do brasileiro Rubem Fonseca, cuja escrita parece tomar duplamente inflexões de cinema e da literatura 
"negras". Falar em noir na obra de Rubem Fonseca implica, pois, considerar procedimentos de recriação, releitura, ocorrência intertextual como retificação de contornos primazes do gênero, às vezes pela via da paródia ou da metaficção, em um "diálogo" que fica a léguas do mero decalque.

Agosto, publicado em 1990, é um romance que - caso não raro, aliás, na obra de Rubem Fonseca - compõe-se pela ambivalência factual-ficcional por associar os principais episódios da crise política brasileira de 1954 que levaria ao suicídio de Getúlio Vargas a um desenho ficcional com os sinais típicos do noir. $\mathrm{O}$ percurso do protagonista da narrativa, o delegado de polícia Mattos, é trajetória modelar do investigador criminal noir - tipo angustiado, torturado por uma úlcera, enredado com duas mulheres, ameaçado por uma trama perigosa - que se funde com os lances dramáticos da vida política do Brasil nos anos de 1950.

Mesmo sumariamente, é preciso ir ao texto de Agosto. Ao seu início:

O porteiro da noite do edifício Deauville ouviu o ruído dos passos furtivos descendo as escadas. Era uma hora da madrugada e o prédio estava em silêncio.

"Então, Raimundo?"

"Vamos esperar um pouco", respondeu o porteiro.

"Não vai chegar mais ninguém. Já está todo mundo dormindo."

"Mais uma hora."

"Amanhã tenho que acordar cedo."

O porteiro foi ate a porta de vidro e olhou a rua vazia e silenciosa.

"Está bem. Mas não posso demorar muito."

No oitavo andar.

A morte se consumou numa descarga de gozo e de alívio, expelindo resíduos excrementícios e glandulares - esperma, saliva, urina, fezes. Afastou-se, com asco, do corpo sem vida sobre a cama ao sentir seu próprio corpo poluído pelas imundícies expulsas da carne agônica do outro. 
Foi ao banheiro e lavou-se com cuidado sob o chuveiro do box. Uma dentada no seu peito sangrava um pouco. No armário da parede havia iodo e algodão, que serviram para um curativo rápido.

Apanhou sua roupa sobre a cadeira e vestiu-se, sem olhar para o morto, ainda que tivesse a aguda consciência da presença do mesmo sobre a cama.

Não havia ninguém na porta quando saiu (FONSECA, 1990, p. 7).

O leitor está diante de alguns traços da típica escrita de Rubem Fonseca, dedicada à exploração do asqueroso, em que o discurso busca o impacto pelo destaque ao excrementício das funções corporais no ápice do suplício físico. Trata-se de um estilo que busca impactar também por narrar a ação brutal com dicção de discurso médico forense do legista criminal. Ao mesmo tempo, a narração configura um assassínio tão breve quanto chocante. Em Rubem Fonseca uma escrita da violência e do grotesco se dá, pois, com a enfática construção lacunar, que se presta a dizer o mínimo, à medida que o discurso explora o choque pela crueza do elemento excrementício.

Assinalo deste início da narrativa seu caráter lacônico. Nos dois fragmentos, separados pela espacialidade da página, mas coabitantes do cenário do edifício Deauville, dá-se pouco, muito pouco ao leitor. O estilo é seco, direto: a narração explora o mínimo para centrar-se na ação e no seu efeito imediato. Como uma espécie de procedimento behaviorista, tudo é exterioridade. O discurso explora a superfície do sensorial; linguagem descarnada com apelo à visualidade. $\mathrm{O}$ primado da ação faz com que as categorias de espaço, tempo e personagem se dêem em notação muito sucinta, com o mínimo de elementos: porteiro, edifício, ruídos de passos, uma hora da manhã, silêncio. O diálogo é furtivo para uma ação curta e escondida entre as personagens. O leitor não sabe quem é o interlocutor do porteiro - talvez uma mulher que o convida ao sexo. No segundo fragmento, uma frase nominal sinaliza 
laconicamente o espaço da ação com a indicação "no oitavo andar", o que estabelece a aproximação espacial, o edifício Deauville, com a ação anterior. Bruscamente, o parágrafo seguinte, o mais longo do trecho, enuncia a ação assassina: "A morte se consumou numa descarga de gozo e de alívio, expelindo resíduos excrementícios e glandulares - esperma, saliva, urina, fezes".

Não há notação de motivações ao que transcorre, pois os componentes do discurso convergem para um ato dão relevo a uma ação, a ocorrência assassina. E o laconismo da linguagem arroja ao leitor o efeito do precário, do incerto. Ele é lançado ao sinóptico misterioso. Um mundo reservado é devassado pelo poder de observação de um narrador onisciente que, no entanto, pouco revela ao leitor. De fato, esse narrador move um olhar que vê sem submergir, tem uma voz que o anuncia sem dizer muito. Prefere mover-se na superfície dos eventos, não explora, nem sequer alude, a dimensões "psicológicas" das personagens. Ardiloso, afeito à negaça, ao jogo de velar e desvelar, o narrador assinala os seres que se esbatem, na penumbra. A condição desses seres advém da ação física; eles só possuem as sumaríssimas categorias de assassino e vítima. Não chegam a atingir plenamente a condição de personagens; são dois corpos em luta.

Passo agora à minissérie Agosto, produção da TV Globo, (autoria de Jorge Furtado e Giba Assis Brasil e direção geral de Paulo José) exibida em 1993. A vinheta de abertura traz a tela seccionada com imagens de figuras e acontecimentos históricos da crise política brasileira de 1954. São fotos e filmes de arquivo de Carlos Lacerda, do guarda pessoal de Getúlio Vargas, Gregório Fortunato, do próprio Vargas acenando para multidões e de seu tumultuado e lacrimoso funeral. A segmentação de tais imagens na tela evoca a diagramação de página de jornal.

Mas, veloz, surge um rasgo amarelo: uma espécie de projétil irrompe de dentro das imagens e as perfura. Como um cometa, é figuração de uma bala que reiteradamente cava e atravessa as imagens, aludindo a eventos históricos trágicos e violentos de 
1954; até furar as próprias letras do título, Agosto, alojando-se nelas. Esse ícone implacável, que delineia um percurso perfurante e incandescente, tanto se lança ao "alvo" do evento trágico da História - o tiro desferido a Carlos Lacerda na Rua Tonelero e a própria bala que matou Vargas - quanto serve para associar a minissérie à ficção policial noir como gênero literário-cinematográfico em que a ocorrência criminosa é motivo indispensável.

Depois, na tela negra em que se inscrevem uma data e um horário (01 de agosto de 1954) - procedimento recorrente na minissérie para a demarcação cronológica que acompanha todo o mês de agosto -, o início prefere distender a diegese, pois acrescenta material narrativo ao micro evento do início do romance de Rubem Fonseca. Um plano traz a imagem de luzes desfocada, que, todavia, vai se tornando nítida para revelar os faróis de um automóvel negro circulando pela noite vazia. O movimento do automóvel negro é delineado pela oscilação de seus faróis em consórcio com a câmera; explora-se o forte contrate entre as luzes dos faróis do carro e a escuridão da cidade. Há uma engenharia de planos, com distintos "takes", com a câmera ora aproximada ora distanciada desse objeto insistentemente observado. As variações de posição de câmera enfatizam o que o automóvel desempenha: um plano traz sua imagem refletida em poça de água da rua, outro o enquadra de cima para captar seu luxuoso capô, em outro a câmera inclinada flagra sua trajetória diagonal, outro é um plano detalhe de um dos seus faróis, que reflete os ambientes da cidade. A ênfase ao transitar do carro misterioso - não se vê nunca o motorista - é estratagema para incitar expectativas: com que propósito esse automóvel negro percorre as ruas escuras e adormecidas da cidade? Até que um ângulo flagra a sua passagem pela frente de um prédio suntuoso, de cuja entrada sai um porteiro, às pressas, para abrir a garagem. 


\section{Verniz noir}

Tal início da minissérie é suficiente para a inscrição inequívoca e aturada da estilística noir como padrão que percorrerá toda a narrativa audiovisual. A minissérie se dedicará a um labor plástico em que a representação dos anos 1950 encontra no noir a via para uma estilização. No transcorrer de todos os capítulos, a minissérie lançará suas fichas plásticas para moldar uma atmosfera de obscuridade derivada das produções cinematográficas americanas dos anos de 1940 e 1950, com uma palheta de cores que não raramente varia entre o sépia e o amarelo. Uma vez que a trama da minissérie - assim como no romance de Rubem Fonseca - transcorre em agosto de 1954 e sendo a década de 50 o período de apogeu do filme noir americano, a adaptação televisiva "adota-o" em seu regime visual, mas o faz pela via da estilização e do clichê. A estilização do noir resulta, pois, em emblema plástico da representação dos anos 50.

A minissérie dá demão do verniz do glamoroso na operação de embaralhar os dados da história com a estilização do discurso historiográfico. Os perigos e segredos da trama do romance de Rubem Fonseca são pintados com a insígnia dos "anos dourados" brasileiros. A palheta de cores insiste no amarelo, no pastel e no laranja para uma apresentação edulcorada dos anos 50 . Não há modulações drásticas de tonalidade de cor, mas variações sutis, em associação com os contrastes entre luz e sombra.

Eis o ponto fundamental: o tratamento estético traduz-se se em esteticismo, ou seja, em uma estrutura visual que decalca - não recria o protótipo cinematográfico do "filme negro". $\mathrm{Na}$ mesma cena do crime misterioso que dá início à trama e é núcleo a partir do qual se desenrola o novelo narrativo, o contraste entre luminosidade e sombra - espécie de insígnia da estética expressionista e noir - imprime-se na luta corporal entre assassino e vítima. Em outras cenas, na sala do comissário Mattos, sombras das persianas formam linhas em sua camisa branca, clichê visual afim à composição prototípica das personagens. O tipo físico 
e o desempenho de José Mayer, aliás, são um adesivo de um Humphrey Bogart, Robert Mitchum ou Burt Lancaster. Já Letícia, a prostituta por ele apaixonada, comparece em muitas cenas de luvas negras, e vestido preto bem atado ao corpo, extração de certa mitologia hollywoodiana à moda Gilda/Rita Hayworth. O regime visual da minissérie acessa outros espécimes, como o filme de gângster, gênero fronteiriço ao policial noir, como em uma cena de reunião dos bicheiros, os contraventores que na trama se situam no território oposto ao do protagonista. A ambientação cenográfica, a iluminação em meios tons e o "casting" afluem para uma evocação reconhecível: o universo de The Godfather (1972, 1974, 1990) de Coppola. No fim da cena, a associação dos três bicheiros à "italianidade" mafiosa se faz pelo entoar em uníssono de um trecho da tradicional canção napolitana "Santa Lucia". Do noir ao filme de gângster, o regime estilístico assinala com tinta espessa insígnias, signos hipercodificados ofertados à fácil identificação do espectador: clichês.

Uma das manifestações desse esteticismo está no delineamento do espaço-tempo. As transições que marcam intervalos de tempo, por exemplo, na passagem de um dia para outro, por exemplo, trazem reiteradamente imagens do Rio de Janeiro como espécies de cartões postais cuja estilização enfatiza o sombrio, o nublado ou o fim de tarde enevoado, tingido de dourado ou cinza escuro. A então Capital Federal se apresenta como uma cidade noturna e, quando de dia, esmaecida, com o alaranjado do crepúsculo ou nublada - o pão de Açúcar envolto em névoa. Em cena em que o personagem responsável pelos assassinatos, o empresário Loganmo, conversando com o matador Chicão em frente ao mar, o dia está nublado. Em seus ambientes internos e externos, o Rio de Janeiro é como uma Chicago ou Nova Iorque nevoenta, sombria, cidade noir prototípica.

Em suma, a minissérie labora recursos hipercodificados, põe em circulação procedimentos de uma codificação fossilizada, emblemas estilísticos do cinema noir americano que há décadas se 
pulverizaram em produções de histórias policiais do amplo campo audiovisual. A tônica são a redundância e a convenção, no encalço de uma eficiência comunicativa da representação de um passado do Brasil que atinge o didático-enciclopédico da historiografia.

Sendo o noir uma estética pulverizada, disseminada, reciclada, espraiada indefinidamente, a minissérie repõe os emblemas do gênero como forma visual que denuncia uma "fonte" literário-cinematográfica. O intertexto da adaptação abarca o cinematográfico com a atitude reverente que (re) estiliza as convenções do noir cinematográfico. A princípio, o noir da minissérie busca acessar o noir em Rubem Fonseca, mas sua inscrição no clichê, na composição dos estilemas do gênero caminho afim segundo exigências de audiência -, parece fundar um decisivo desacordo com a obra literária.

\section{Clichê e crueza}

Entre outros aspectos, a obra de Rubem Fonseca é conhecida como feitura literária que reelabora a narrativa policial, dialoga com a tradição do gênero noir e, ao mesmo tempo, escrita que (re) pisa a interlocução cinema-literatura. Nesse Caminho, o romance Agosto convidaria a uma discussão - que excede o propósito deste artigo - a respeito das relações entre literatura e cultura de massa. Uma perspectiva poderia apontar o romance como exemplo cabal de acoplamento da literatura à voragem mercadológica das últimas décadas, o que representaria a própria decadência da expressão literária. Outra, talvez mais cautelosa, diria ser tal obra exemplar de uma relação intrincada entre o literário e a cultura de massa, interstício dialético entre "alta" e "baixa" cultura.

Interessa-me assinalar em Agosto - o que é válido para a obra literária de Fonseca como um todo e também reflete certo vetor da produção literária mundial contemporânea - a inflexão intertextual da cultura midiática audiovisual. Uma "escrita cinematográfica" seria um dos feixes da obra de Fonseca. Não 
cabe aqui uma análise detida de como se dá o "cinematográfico" em Rubem Fonseca. Vale, de qualquer modo, apontar que os "procedimentos cinematográficos" de sua escrita concebem um processo de transcodificação como construção de correlativos da expressão verbal à expressão audiovisual; o sistema de signos verbais promove analogias para um "efeito cinematográfico". Assim, falar em "influência" do repertório cinematográfico na obra de Rubem Fonseca só é pertinente se se considerar como sua escrita mobiliza uma cultura audiovisual nos termos da transcodificação. $\mathrm{O}$ caráter intertextual em Rubem Fonseca é expressão de uma "assimilação" do cinematográfico como tradução intersemiótica. Assim, o literário é expressão intertextual em que o diálogo cinema-literatura funciona como um eixo em que estão ligados, no fim das contas, tema e forma: o mundo do crime e a investigação criminal própria do filme policial noir é coligada a uma forma verbal em cujos lances lúdicos está o horizonte técnico-estético do cinema; uma obra que "adapta" o código cinematográfico no cerne da estrutura narrativa e no constructo do significante. Uma vez adaptados para o cinema e televisão, os romances e contos de Rubem Fonseca seriam, então, "devolvidos" ao território de interação entre o literário e o audiovisual.

A parcela da obra de Rubem Fonseca mais impregnada do universo do policial noir em romances como A Grande Arte (FONSECA, 1983), Bufo e Spallanzani (FONSECA, 1985), Vastas emoções e pensamentos imperfeitos (FONSECA, 1988), E do meio do mundo prostituto só amores guardei ao meu charuto (FONSECA, 1997) e em um conto cujo título explicita o próprio gênero, "Romance Negro", do livro romance negro e outras histórias (FONSECA, 1992), além é, claro, de Agosto (FONSECA, 1990), a etiqueta de romance policial noir não se acondiciona de modo confortável, havendo um movimento problemático. Em larga medida há uma assimilação que chega a transgredir contornos do gênero ou produzir-lhe dissonâncias. A fixação em contexto degenerado se dá com uma escrita na qual a violência no plano 
temático só encontra validade na forma de expressão. Sua condição propriamente literária é a de uma escrita enformada do paroxismo da violência urbana.

No cerne dessa violência lavrada no plano da linguagem, os componentes do noir não servem ao entretenimento reconfortante. Abandonam-se ingredientes típicos do gênero como a resolução satisfatória do crime e a superioridade - por mais que sua moral seja dúbia, caso de Hammett - do investigador criminal. Há uma fissura em valores como "o crime não compensa" ou no triunfo da justiça, portadores de uma espécie de função compensatória da narrativa diversional massiva. Agosto possui tal postura que está distante da mera clonagem de cacoetes do noir literário norte-americano. $\mathrm{O}$ repertório da tradição noir sofre na escrita de Fonseca, pois, uma assimilação transformadora.

Tudo isso assinala um desacordo fundo entre a fatura estética do romance e sua adaptação pela minissérie aqui avaliada. Se a literatura de Rubem Fonseca afasta o clichê, a adaptação da TV Globo abraça-o. O polimento glamoroso da minissérie caminha em direção oposta ao escatológico da escrita de Rubem Fonseca. Ela acolhe a "matriz" norte-americana pela estilização que edulcora o universo da narrativa policial. Ao contrário do movimento de uma assimilação problemática operada pela obra de Fonseca, que chega a contrariar componentes estruturais do romance policial noir padrão, a minissérie adota no decurso narrativo uma estrutura visual que em nenhum momento põe em crise - sequer ameaça desestabilizar - um padrão estilístico fossilizado.

\section{Território de escambos}

Mas, se apontei um desacordo entre a obra literária de Rubem Fonseca e sua adaptação televisiva, o que, em termos sumários, opõe a crueza do romance ao clichê da estrutura visual da minissérie, tal julgamento em nenhuma parte representa endosso à noção de "fidelidade". 
A propósito, a noção de "fidelidade" permeou por um período considerável a discussão e o próprio julgamento da adaptação literária ao audiovisual. Nessa perspectiva, bem sucedidas seriam aquelas adaptações que conseguiriam conduzir com "integridade" o universo e o "espírito" da obra literária fonte para o campo audiovisual. Relevantes contribuições teóricas, no entanto, provenientes dos estudos linguísticos, semióticos, da teoria da literatura, dos estudos da imagem e da teoria do cinema, levaram a um questionamento crucial da noção "fidelidade", apontando aí um equívoco fomentador de uma exigência tão despropositada quanto ingênua. Assim, Robert Stam, em seu A Literatura através do cinema (STAM, 2008), rejeita a noção de "fidelidade" como princípio metodológico no tratamento do problema da adaptação. Também Julio Plaza, em Tradução Intersemiótica (PLAZA, 2010) recusa com rigor a noção de "fidelidade" para empreender análises de expressões da tradução no campo da poesia, das artes visuais e do cinema. Intérprete perspicaz do nosso cinema, Ismail Xavier em mais de uma ocasião assinala que no processo de adaptação o filme deve ser apreciado "como nova experiência que deve ter sua forma, e os sentidos nela implicados, julgados em seu próprio direito" (XAVIER, 2003, p. 62). Também Ana Maria Balogh (2004), pela via da semiótica francesa, labora com a noção de transmutação ou tradução intersemiótica: sistemas de signos não verbais que interpretam ou recriam signos verbais. Os saldos analíticos de Balogh abrigaram contribuições de "Da Transcriação: Poética e Semiótica da Operação Tradutora” (CAMOPOS, 1987), conhecido ensaio de Haroldo de Campos. Mais atrás, Paulo Emílio Salles Gomes assinalava, mesmo que de modo tênue, afastamento da noção de "fidelidade". Em "A Personagem Cinematográfica", ensaio do livro A Personagem de Ficção (GOMES, 1964), se por um lado Paulo Emílio identifica pontos de contato entre literatura (romance) e cinema, é muito ciente das fundamentais divergências entre as duas formas de expressão.

Guardadas as peculiaridades teóricas e de método, tais 
contribuições se afinam na afirmação de que toda adaptação/ tradução intersemiótica implica inevitavelmente deliberações de um sistema de signos alheio ao sistema de origem. A inalcançabilidade da "fidelidade" entre texto original e sua adaptação é flagrantemente mais intensa na tradução intersemiótica, em que se busca traduzir um texto de um sistema semiótico para outro. A intersemioticidade é intrinsecamente contrária à noção de "fidelidade". Assim, toda tradução intersemiótica só pode ser franco processo de recriação, uma vez que o ato de traduzir torna-se um processo de operar escolhas criativas no centro da conversão de uma obra pertencente a um sistema de signos em outra obra pertencente a outro sistema. É inerente à própria escolha de um sistema de signos que a linguagem percorra outros caminhos, próprios da sua estrutura. Toda adaptação é, intrinsecamente, indução de novas realidades. Diversos são os efeitos de sentido e, por tabela, a fruição do receptor. Nenhuma adaptação pode ser, pois, acusada de "traição" do original, como nenhuma pode ser considerada "fiel". Produz-se, no máximo, um efeito de semelhança à obra fonte com o manejo de correlativos de linguagem, expedientes de analogia de um sistema em relação a outro.

Se aparentemente a minissérie Agosto teria se aferrado à matriz estilística do "filme negro" como recurso de laboração de um correlativo semiótico à obra literária fonte, busquei demonstrar que, tendo o noir em sua estrutura visual se recoberto de uma fossilização que se traduz em clichê, há um desacordo drástico com o modo pelo qual a obra de Rubem Fonseca incorpora a tradição da "narrativa negra". Agosto, a minissérie, em nenhum momento busca configurar alguma associação, no âmbito do sistema semiótico a que pertence, o audiovisual televisivo, uma aclimatação do cinema noir americano, como fizera a literatura de Rubem Fonseca no manejo de seus expedientes no sistema literário. Enquanto a literatura de Fonseca nunca se posta nos termos de decalque da "matriz" do noir, mas a problematiza como espécie de "resposta" de um escritor latino-americano em contexto histórico distinto da 
produção literária e cinematográfica norte-americana, a minissérie põe em ação dispositivos que buscam configurar um estilo - na acepção assumida por Bordwell (2013) - do universo do filme noir, decalcando-lhe procedimentos estéticos. Enquanto em Rubem Fonseca o noir é submetido a uma reconfiguração que ultrapassa qualquer dicção submissa ou parafrástica; a minissérie Agosto realiza uma espécie de dublagem audiovisual de seus contornos fossilizados.

\section{Como uma conclusão}

Chegado aqui, reitero o caráter exemplar dessa avaliação breve do "caso" Agosto. Como outros gêneros, o noir se pulverizou na contemporaneidade em um sem número de manifestações da ficção midiática - e da própria literatura. No exemplo já aqui citado de Sin City, adaptação cinematográfica de uma série de quadrinhos, o noir é recoberto pela tinta da hiperinflação dos emblemas do gênero. A saturação visual de Sin City é reiteração das feições surradas do gênero, mas recicladas, envoltas em uma embalagem aliciadora - plasticidade que se nomearia de cosmética - pelos recursos da tecnologia digital.

Amalgamado a traços de outros gêneros e distintos procedimentos narrativo-estéticos da ficção contemporânea, em seriados de TV, histórias em quadrinho, games, animações e, claro, o próprio cinema, o caminho do noir é uma constante reciclagem e hibridização. Seu lastro nos franqueia o flagrante da voracidade dos trânsitos e escambos entre gêneros e estéticas narrativas, à notação da intensa capacidade de interconexão e contaminação entre as formas da ficção midiática. O caminho da mão dupla, ou seja, a contaminação recíproca entre cinema e literatura que acompanharia a trajetória do noir, se torna no fim das contas insuficiente. Afinal, a cultura midiática contemporânea está marcada pela troca voraz de diversos procedimentos e expedientes no interior da convergência e 
diálogo entre vários meios em contexto transnacional.

Mais do que em qualquer outro tempo, a adaptação é hoje um fenômeno intermidiático. Longe de se tratar de algo novo, o fenômeno vive na contemporaneidade, todavia, uma intensidade sem precedentes pelas convergências e toda sorte de ligaduras, contaminações entre dispositivos, plataformas e meios; ela habita um panorama de extraordinários e aturados intercâmbios, voláteis contaminações, trânsitos, composições e recomposições. O correlato de tal dinâmica produtiva é um consumo e uma fruição afeitos ao próprio intercambiar, ao constante permutar dos códigos e gêneros. Produtos narrativos partem de contextos anteriores nem sempre do repertório literário - e encontram um consumidor extremamente desenvolto no ato de usar e descartar, intercambiar, deslocar e absorver formas ficcionais e gêneros diversos.

Saliente-se, pois: a questão da adaptação deve ser tomada pela dinâmica mesmo da reciprocidade constante de expedientes ficcionais, ajuizada num circuito de intensa manipulação de referências, ponderada sempre com a constatação da permeabilidade irreprimível das formas narrativo-ficcionais. O vasto universo do ficcional nunca foi alheio aos trânsitos de procedimentos formais, o que inclui os "velhos" modos de contar histórias. O que pode ser considerado saliente é que nas últimas décadas a cultura midiática intensificou extraordinariamente tais câmbios no âmbito de novas graças tecnológicas.

Se o problema da adaptação na contemporaneidade só pode ser flagrado nesse horizonte, o noir em Agosto parece servir, segundo o percurso delineado neste artigo, como manifestação exemplar, no circuito literatura-televisão-cinema. Desse modo, não se perde a associação texto-contexto, a conjunção entre as formas de expressão e suas condições peculiares de produção e difusão: trabalho indispensável - quero crer - a toda hermenêutica das expressões narrativo-ficcionais do campo midiático contemporâneo. 


\section{Referências}

BAKHTIN, Mikhail (V. N. Volochínov). Marxismo e filosofia da linguagem: problemas fundamentais do método sociológico na ciência da linguagem. São Paulo: Hucitec, 1988.

BALOGH,AnnaMaria.Conjunções-disjunções-transmutações: da literatura ao cinema e à TV. São Paulo: Annablume, 2004.

BORDWELL, David. Sobre a história do estilo cinematográfico. Campinas: Unicamp, 2013.

CAMPOS, Haroldo. "Da transcriação: poética e semiótica da operação tradutora”. In: OLIVERIA, Ana Cláudia de; SANTAELLA, Lúcia (Org.). Semiótica da literatura. São Paulo: Educ, 1987. (Cadernos Puc, n. 28).

FONSECA, Rubem. A grande arte. Rio de Janeiro: Francisco Alves, 1983.

FONSECA, Rubem. Agosto. São Paulo: Companhia das Letras, 1990.

FONSECA, Rubem. Bufo \& Spallanzani. Rio de Janeiro: Francisco 
Alves, 1985.

FONSECA, Rubem. E do meio do mundo prostituto só amores guardei ao meu charuto. São Paulo: Companhia das Letras, 1997.

FONSECA, Rubem. Romance negro e outras histórias. São Paulo: Companhia das Letras, 1992.

FONSECA, Rubem. Vastas emoções e pensamentos imperfeitos. São Paulo: Companhia das Letras, 1988.

GOMES, Paulo Emílio Sales. A personagem cinematográfica. In: CANDIDO, Antonio et al. A personagem de ficção. São Paulo: Faculdade de Filosofia, Ciências e Letras da Universidade de São Paulo, 1964.

MATTOS, A. C. Gomes de. O outro lado da noite: filme noir. Rio de Janeiro: Rocco, 2001.

PALLOTTINI, Renata. Dramaturgia de televisão. 2. ed. São Paulo: Perspectiva, 2012.

PLAZA, Julio. Tradução intersemiótica. 2. ed. São Paulo: Perspectiva, 2010. 
SILVER, Alain; URSINI, James. The noir style. Woodstock:

Overlook, 1999.

STAM, Robert. A literatura através do cinema: realismo, magia e a arte da adaptação. Belo Horizonte: UFMG, 2008.

XAVIER, Ismail. Do texto ao filme: a trama, a cena e a construção do olhar no cinema. In: PELLEGRINI, Tânia et al. Literatura, cinema e televisão. São Paulo: Instituto Itaú Cultural, 2003. 